\title{
Regional lung function in unilateral diaphragmatic paralysis
}

\author{
JOHN B. RIDYARD and RUSSELL M. STEWART ${ }^{1}$ \\ Regional Cardio-Thoracic Centre, Broadgreen Hospital, Liverpool L14 3LB
}

\begin{abstract}
Ridyard, J. B. and Stewart, R. M. (1976). Thorax, 31, 438-442. Regional lung function in unilateral diaphragmatic paralysis. Radioactive xenon-133 was used to study the regional lung function of five patients with unilateral diaphragmatic paralysis unassociated with intrathoracic disease. All patients showed a reduction in total lung capacity to which the affected side contributed an average of $37 \%$. There was a decrease in the amount of inhaled xenon and a lesser decrease in the amount of injected xenon reaching the lung base on the paralysed side. The distribution in the opposite lung did not differ significantly from that found in normal subjects although the proportion of inhaled xenon reaching the lung base was rather less than in the normal group. The washout of injected xenon was normal except for slight impairment at the lung base on the paralysed side in one patient and at both bases in another.
\end{abstract}

So far as we are aware, the only previous account of regional lung function in diaphragmatic paralysis is the recent report by Arborelius, Lilja, and Senyk (1975). These authors studied 17 patients in various postures. In nine of these, the phrenic paralysis followed transthoracic transdiaphragmatic repair of hiatus hernia. No comparison was made with normal subjects.

The object of the present paper is to report overall lung function and the regional distribution of ventilation, perfusion, and lung volume in a group of five patients with unilateral diaphragmatic paralysis, unassociated with intrathoracic disease, and to compare these with the distribution patterns in 14 normal control subjects of comparable age.

\section{SUBJECTS}

Clinical details of the five patients are shown in Table I. There were two men and three women. The phrenic paralysis was on the right side in all but one case. All were lifelong non-smokers, except for IM, who had smoked until six months before the study.

In two of the patients there was no evident cause for the paralysis. In one patient it followed an attack of herpes zoster, and this has previously been reported as a cause for phrenic paralysis

'Present address: Fellow in Pulmonary Disease, The Johns Hopkins Hospital, Baltimore, Maryland, USA
(Dutt, 1970; Leading article, British Medical Journal, 1970). The fourth patient was found to have hypothyroidism, which is another known $\mathbb{\triangle}$ cause of neuropathy (Nickel et al., 1961). The $\overrightarrow{\vec{t}}$ phrenic paralysis in the fifth was discovered after an accident involving a brachial plexus injury.

Effort dyspnoea was the principal symptom in four patients, and one of these patients also com plained of orthopnoea. The fifth patient was symptom free. All patients showed paradoxical movement of the diaphragm on sniffing.

The 14 control subjects were lifelong nonsmokers with no history of lung or heart diseasc. $\delta$ They had normal chest radiographs, lung function tests, and electrocardiograms.

\section{METHODS}

The methods used are those described in the preceding paper (Stewart, Ridyard, and Pearson, $N$ 1976). However, in the present paper, the results were calculated so as to permit a comparisono between the two lungs of each patient. The distri-o bution indices of perfusion and inhalation per $\frac{\mathscr{}}{\mathbb{D}}$ unit volume for each of the six lung zones were $\stackrel{?}{+}$ therefore expressed as a percentage of the mean $\square$ distribution index for both lungs together. Since $\stackrel{P}{D}$ the division into zones was based on the equilibra- $\stackrel{\mathbb{D}}{\Omega}$ tion scan and the indices were expressed per unit $\mathbb{\mathbb { Q }}$ of alveolar volume, the results should not be in- 
T A B L E I

CLINICAL FINDINGS

\begin{tabular}{|c|c|c|c|c|c|c|}
\hline Patient & Age & Sex & $\begin{array}{c}\text { Side } \\
\text { affected }\end{array}$ & $\begin{array}{c}\text { Smoking } \\
\text { Habits }\end{array}$ & $\begin{array}{c}\text { Probable Cause of } \\
\text { Paralysed } \\
\text { Hemidiaphragm }\end{array}$ & Symptoms \\
\hline EB & 66 & $\mathbf{F}$ & Right & Nil & $\begin{array}{l}\text { Herpes zoster of } \\
\mathrm{C} 3, \mathrm{C} 4, \mathrm{C} 5\end{array}$ & $\begin{array}{l}\text { Dyspnoea climbing } \\
\text { one flight of } \\
\text { household stairs }\end{array}$ \\
\hline EH & 58 & F & Right & Nil & Hypothyroidism & $\begin{array}{l}\text { Dyspnoea and } \\
\text { lassitude }\end{array}$ \\
\hline IM & 54 & $\mathbf{F}$ & Right & $\begin{array}{l}30 \text { cigs/day until } \\
6 \text { mth before } \\
\text { study }\end{array}$ & Unknown & None \\
\hline DS & 33 & $\mathbf{M}$ & Right & Nil & Unknown & $\begin{array}{l}\text { Right-sided chest } \\
\text { pain on effort. } \\
\text { Dyspnoea on running } \\
18 \mathrm{mth}\end{array}$ \\
\hline HN & 42 & $\mathbf{M}$ & Left & Nil & $\begin{array}{l}\text { Trauma to } \\
\text { brachial plexus }\end{array}$ & $\begin{array}{l}\text { Orthopnoea with } \\
\text { palpitations, } \\
\text { dyspnoea on running }\end{array}$ \\
\hline
\end{tabular}

fluenced by the higher position of the diaphragm on the paralysed side.

\section{RESULTS}

OVERALL LUNG FUNCTION The results for overall lung function are shown in Table II.

The vital capacity was reduced in all the patients with a range of 62 to $86 \%$ of predicted and a mean of $73 \%$. The total lung capacity was also reduced in all patients with a range of 46 to $83 \%$ of predicted and a mean of $71 \%$. The forced expired volume in one second as percentage of vital capacity was normal in every case and the transfer factor (measured in three patients) was also normal.

REgIONAL LUNG FUnCtion Figure 1 and Table III show the proportion of inhaled xenon per unit lung volume for each of the three lung zones, comparing the paralysed and unaffected sides. The standard deviations are also shown. Statistical analysis of the results using Student's $t$ test indicates a significant reduction in basal ventilation on the paralysed side as compared with the opposite side $(\mathrm{P}<0.001)$.

Figure 2 and Table III show the regional distribution of perfusion in a similar manner. There is a significant reduction of basal perfusion on the

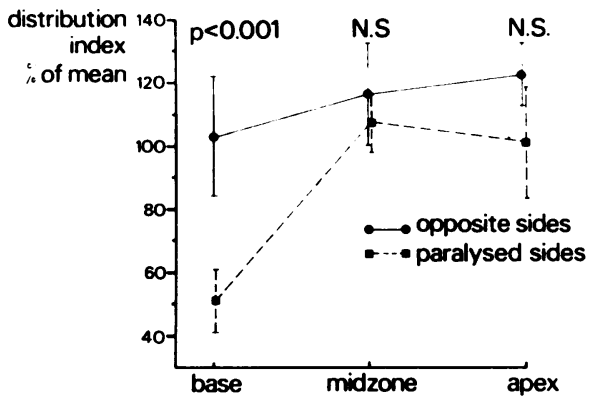

FIG. 1. Mean distribution indices for inhalation comparing the paralysed sides in each of the three zones with the opposite sides. The vertical lines show the standard deviations. Statistical analysis is shown.

T A B L E I I

OVERALL LUNG FUNCTION

\begin{tabular}{|c|c|c|c|c|c|c|c|c|c|}
\hline \multirow[b]{2}{*}{ Patient } & \multicolumn{2}{|c|}{ Vital Capacity } & \multirow{2}{*}{$\begin{array}{l}\text { FEV }_{1} \\
\text { (Litres) }\end{array}$} & \multirow{2}{*}{$\frac{\mathrm{FEV}_{1} \%}{\mathrm{VC}}$} & \multirow{2}{*}{\multicolumn{2}{|c|}{$\begin{array}{c}\text { Residual Volume } \\
\text { Litres \% Pred. }\end{array}$}} & \multirow{2}{*}{\multicolumn{2}{|c|}{$\begin{array}{c}\begin{array}{c}\text { Total Lung } \\
\text { Capacity }\end{array} \\
\text { Litres \% Pred. }\end{array}$}} & \multirow{2}{*}{$\begin{array}{c}\text { Transfer Factor } \\
\text { (\% Pred.) }\end{array}$} \\
\hline & Litres & $\%$ Predicted & & & & & & & \\
\hline $\begin{array}{l}\text { EB } \\
\text { EH } \\
\text { IM } \\
\text { DS } \\
\text { HN }\end{array}$ & $\begin{array}{l}1 \cdot 55 \\
1 \cdot 90 \\
2 \cdot 15 \\
4 \cdot 10 \\
2 \cdot 90\end{array}$ & $\begin{array}{l}62 \\
73 \\
80 \\
86 \\
64\end{array}$ & $\begin{array}{l}1.25 \\
1.25 \\
1.55 \\
3.6 \\
2.25\end{array}$ & $\begin{array}{l}81 \\
67 \\
72 \\
88 \\
78\end{array}$ & $\begin{array}{l}0.66 \\
1.69 \\
1.75 \\
0.87 \\
1.75\end{array}$ & $\begin{array}{l}35 \\
94 \\
97 \\
47 \\
92\end{array}$ & $\begin{array}{l}2 \cdot 06 \\
3 \cdot 54 \\
3 \cdot 80 \\
5 \cdot 12 \\
4 \cdot 65\end{array}$ & $\begin{array}{l}46 \\
79 \\
83 \\
76 \\
72\end{array}$ & $\frac{104}{\overline{92}}$ \\
\hline
\end{tabular}


T A B L E I I I

MEAN DISTRIBUTION INDICES WITH STANDARD DEVIATIONS FOR INHALATION AND PERFUSION COMPARING THE THREE ZONES ON THE PARALYSED SIDES WITH THOSE ON THE OPPOSITE SIDES

\begin{tabular}{|c|c|c|c|}
\hline & Base & Middle & Apex \\
\hline $\begin{array}{c}\text { Inhalation indices } \\
\text { Paralysed sides } \\
\text { Opposite sides }\end{array}$ & $\begin{array}{c}51 \\
102 \cdot 8\end{array} \stackrel{ \pm 10 \cdot 3}{ \pm 18 \cdot 6}$ & $\begin{array}{l}107 \pm 9 \cdot 8 \\
116 \pm 16 \cdot 7\end{array}$ & $\begin{array}{l}100 \cdot 6 \pm 18 \cdot 2 \\
122 \cdot 2 \pm 10 \cdot 2\end{array}$ \\
\hline $\begin{array}{c}\text { Perfusion indices } \\
\text { Paralysed sides } \\
\text { Opposite sides }\end{array}$ & $\begin{array}{l}66 \cdot 4 \pm 8 \cdot 1 \\
88 \cdot 4 \pm 12 \cdot 2\end{array}$ & $\begin{array}{l}109.6 \pm 14 \cdot 1 \\
104 \cdot 8 \pm 10.9\end{array}$ & $\begin{array}{l}111 \cdot 2 \pm 9.5 \\
119.2 \pm 12 \cdot 0\end{array}$ \\
\hline
\end{tabular}

The numerical form of Figs 1 and 2.

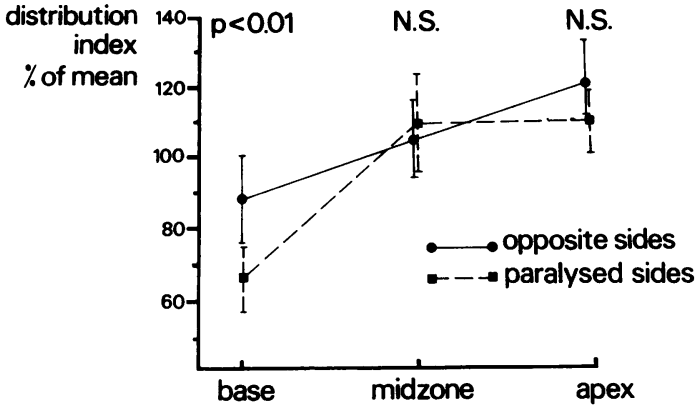

FIG. 2. Mean distribution indices for perfusion comparing the paralysed sides in each of the three zones with the opposite sides. The vertical lines show the standard deviations. Statistical analysis is shown.

paralysed side as compared with the opposite side $(\mathrm{P}<0.01)$, but this is of lesser degree than the reduction in ventilation.

In Figs 3 and 4 and Table IV, the distribution of inhaled and perfused xenon in the lung opposite to the paralysed diaphragm is compared with the distribution in the 14 healthy control subjects. There is no significant difference between the patients and normal subjects although there is a tendency towards reduced basal ventilation in the lung opposite to the paralysed side.

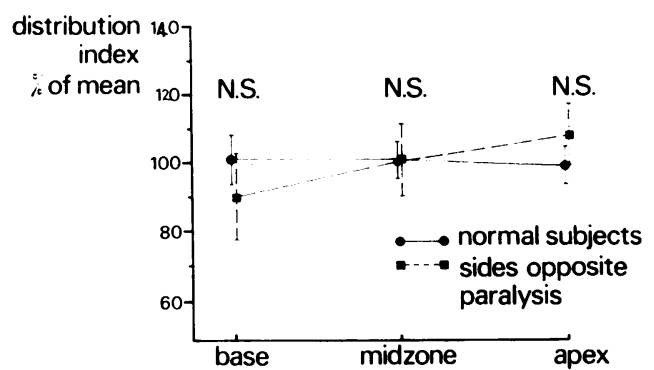

FIG. 3. Mean distribution indices for inhalation comparing the lungs overlying the non-paralysed sides in each of the three zones with the means for 14 normal subjects. The vertical lines show the standard deviations.

The percentage retention of xenon 30 seconds after injection was within normal limits (less than $30 \%$ retained) in three of the five patients in all zones. It was abnormal at the base on the paralysed side in one patient and at both bases in the fifth patient. The mean percentage retention at the base on the paralysed side $(20 \%)$ was greater than 8 on the other side $(13 \%)$. This difference, although $₹$ in keeping with the results of the inhalation o scans, was not significant.

The relative volumes of the two lungs were de- $\frac{T}{O}$

T A B L E I V

MEAN DISTRIBUTION INDICES WITH STANDARD DEVIATIONS FOR INHALATION AND PERFUSION COMPARING THE THREE ZONES IN THE 14 NORMAL SUBJECTS WITH THE THREE ZONES OVERLYING THE NON-PARALYSED SIDES

\begin{tabular}{|c|c|c|c|}
\hline & Base & Middle & Apex \\
\hline $\begin{array}{l}\text { Inhalation indices } \\
\text { Sides opposite paralysis } \\
\text { Normal subjects }\end{array}$ & $\begin{array}{r}90 \cdot 2 \pm 12 \cdot 7 \\
101 \cdot 1 \pm 7.3\end{array}$ & $\begin{array}{l}102.4 \pm 10.6 \\
100.5 \pm 5.4\end{array}$ & $\begin{array}{r}107 \cdot 6 \pm 9.1 \\
98.4 \pm 5.5\end{array}$ \\
\hline $\begin{array}{l}\text { Perfusion indices } \\
\text { Sides opposite paralysis } \\
\text { Normal subjects }\end{array}$ & $\begin{array}{l}84 \cdot 8 \pm 11 \cdot 1 \\
84 \cdot 9 \pm 12 \cdot 0\end{array}$ & $\begin{array}{l}100 \cdot 8 \pm 9.4 \\
102 \pm 5.5\end{array}$ & $\begin{array}{l}114 \cdot 4 \pm 12 \cdot 1 \\
113 \cdot 1 \pm 13 \cdot 1\end{array}$ \\
\hline
\end{tabular}

The numerical form of Figs. 3 and 4. 


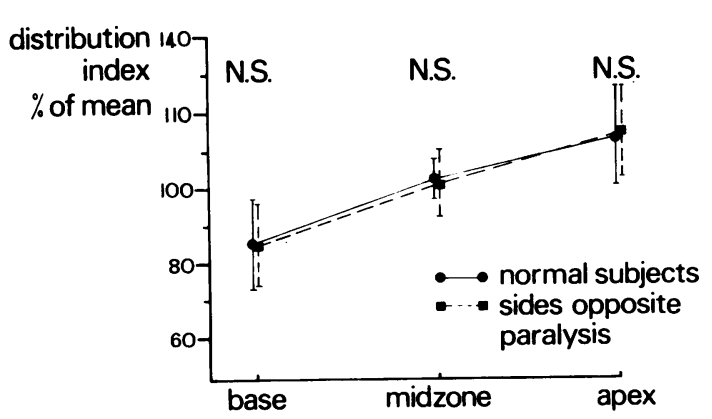

FIG. 4. Mean distribution indices for perfusion comparing the lungs overlying the non-paralysed sides in each of the three zones with the means for 14 normal subjects. The vertical lines show the standard deviations.

T A B L E V

RELATIVE CONTRIBUTION OF EACH LUNG TO TOTAL LUNG VOLUME AS MEASURED AT EQUILIBRATION

\begin{tabular}{c|c|c}
\hline \multirow{2}{*}{ Patient } & \multicolumn{2}{|c}{$\%$ Contribution to Total Lung Volume } \\
\cline { 2 - 3 } & Paralysed Side (Right) & Normal Side (Left) \\
\hline EB & 37 & 63 \\
EH & 41 & 59 \\
IM & 34 & 66 \\
DS & 35 & 65 \\
\hline
\end{tabular}

For technical reasons one patient was omitted. These four patients all had paralysis of the right diaphragm.

rived from the equilibration scan in the four patients with paralysis of the right diaphragm (for technical reasons adequate data were not available for the fifth patient, HN). Table V shows that the right lung was contributing from 34 to $41 \%$ (normal expected, $55 \%$ ) of the total lung volume.

\section{DISCUSSION}

OVERALL LUNG FUNCTION A decrease in vital capacity and total lung capacity would be expected in patients with a paralysed diaphragm and has previously been reported by McCredie, Lovejoy, and Kaltreider (1962) and by Gould et al. (1967). McCredie et al. described three patients with bilateral phrenic paralysis in whom the mean vital capacity was reduced to $50 \%$ of predicted in the erect posture with a further fall, accompanied by orthopnoea, in the supine posture. Two of McCredie's three patients had a normal gas transfer factor. Gould et al. (1967) studied eight patients with an experimentally induced unilateral phrenic paralysis. The mean vital capacity was reduced to $86 \%$ of the original value and the total lung capacity to $91 \%$, falling to $71 \%$ and $80 \%$ respectively in the supine posture. These patients were free of symptoms. Arborelius et al. (1975) studied 17 patients with a paralysed hemidiaphragm and found a mean vital capacity in the sitting position of $\mathbf{7 4 . 6} \%$ predicted and total lung capacity of $86.1 \%$ predicted; however, in more than half these patients the paralysis had followed thoracotomy.

In the present study of naturally occurring unilateral diaphragmatic paralysis without intrathoracic disease, the mean vital capacity in the erect posture was $73 \%$ of predicted and the mean total lung capacity $71 \%$. The gas transfer factor was normal. All but one of the patients noticed effort dyspnoea and one also complained of orthopnoea.

REGIONAL LUNG FUNCTION The principal abnormalities of regional lung function in our five patients with unilateral phrenic paralysis may be summarized as follows:

(1) Lung volumes The paralysed side (right) contributed only $37 \%$ of the total lung capacity (normal: $55 \%$, see Table V) and this presumably accounts for the reduction in vital and total lung capacity already discussed. Arborelius et al. (1975) found that in their 17 patients (of whom 12 had left-sided and five right-sided paralysis) the average contribution to total lung volume of the paralysed side was $41 \cdot 1 \%$.

(2) Ventilation On the paralysed side, inhaled xenon-133 was preferentially distributed to the middle and upper zones (Fig. 1) whereas in the normal subjects distribution was even throughout the three zones (Fig. 3). There was a similar tendency in the lung opposite to the paralysis but the difference from the lungs of the normal subjects was not statistically significant (Fig. 3).

The washout of injected xenon may be regarded as a measure of dynamic ventilation and it is of some interest that this, unlike the distribution of a single breath of inhaled xenon, was normal in three of the five patients. Washout was slightly impaired at the base on the paralysed side in one patient and at both bases in the fifth patient. Experience in this laboratory (Evans, 1973; Seaton, D., personal communication) suggests that xenon washout is more sensitive to airways obstruction than to regional variations in lung expansion or compliance. This is supported by the findings in one patient with a phrenic paralysis but an otherwise normal chest radiograph; the paralysis was attributed to herpes zoster, and the patient had 
originally been admitted to the present study. The xenon washout was normal at the lung base overlying the paralysed diaphragm (less than $30 \%$ retention at 30 seconds) but grossly abnormal at the lung apex (64\% retention). It was not until six months later that de-aeration of the left apexdue to a carcinoma obstructing the left upper lobe bronchus-was evident in the radiograph.

(3) Perfusion Perfusion of xenon-133 was also preferentially distributed to the middle and upper zones on the paralysed side but to a lesser degree than in the case of ventilation. This is a normal finding in the supine posture (see Fig. 4) but basal perfusion was significantly less on the paralysed side than in the opposite lung (Fig. 2). The fact that the basal perfusion defect to some extent matches the ventilation defect is supported by the finding of a normal $\mathrm{PaO}_{2}(14.0 \mathrm{kPa})$ in both the erect and supine postures in subject $H N$. A possible mechanism for this is alveolar hypoxia within basal lung units inducing a localized pulmonary arteriolar constriction.

The perfusion gradient in the lung opposite the paralysis was, unlike the ventilation gradient, identical with that found in the lungs of normal subjects (Fig. 4).

These findings confirm the observations of Arborelius et al. (1975) that both ventilation and perfusion are reduced in the lung overlying a paralysed diaphragm and that this reduction is maximal at the base. The present study also shows that these observations are applicable to patients with extrathoracic causes for phrenic paralysis and that, in comparison with normal subjects, there is no significant abnormality of regional lung function in the opposite lung.
We should like to thank Drs C. M. Ogilvie, W. S. Sutton, C. C. Evans, and D. Seaton for their helpful comments on this paper.

Miss D. A. Pellard, Mrs. L. E. Stewart, and Mrs.

J. E. Lamb gave us invaluable technical assistance.

\section{REFERENCES}

Arborelius, M., Lilja, B., and Senyk, J. (1975). $\vec{\circ}$ Regional and total lung function in patients with hemidiaphragmatic paralysis. Respiration, 32, $\vec{\omega}$ 253.

British Medical Journal (1970). Paralysed hemi- $\overrightarrow{2}$ diaphragm and shingles. Leading article, British Medical Journal, 1, 382.

Dutt, A. K. (1970). Diaphragmatic paralysis caused by herpes zoster. American Review of Respiratory Disease, 101, 755.

Evans, C. C. (1973). Regional and overall pulmonary $\frac{\circ}{2}$ function in bronchial asthma. MD thesis, Univer- sity of Liverpool.

Gould, L., Kaplan, S., McElhinney, A. J., and Stone, 으 D. J. (1967). A method for the production of क hemidiaphragmatic paralysis. American Review of Respiratory Disease, 96, 812.

McCredie, M., Lovejoy, F. W. Jr., and Kaltreider, बे N. L. (1962). Pulmonary function in diaphragmatic paralysis. Thorax, 17, 213.

Nickel, S. N., Frame, B., Bebin, J., Tourtellotte, W. W., Parker, J. A., and Hughes, B. R. (1961). Myxedema neuropathy and myopathy. A clinical and pathological study. Neurology, 11, 125.

Stewart, R. M., Ridyard, J. B., and Pearson, J. D. $\overrightarrow{\vec{O}}$ (1976). Regional lung function in ankylosing spondylitis. Thorax, 31, 000.

Requests for reprints to: Dr. J. B. Ridyard, Regional Cardiothoracic Centre, Broadgreen Hospital, Thomas $\stackrel{\infty}{x}$ Drive, Liverpool L14 3LB. 